\title{
Treatment of fracture of shaft of humerus in adults by intramedullary interlocking nail fixation
}

\author{
P Chaudhary, NK Karn, BP Shrestha, GP Khanal, RPS Kalawar \\ Department of Othopaedics \\ B.P. Koirala Institue of Health Sciences, Dharan, Nepal
}

\begin{abstract}
Backgroud: The optimal method of humeral shaft fracture fixation remains in debate. With the dramatic success of intramedullary fixation for fractures of the femur and tibia, there was speculation that IM-ILN might be more appropriate for humeral shaft fractures than DCP. There are very few studies comparing intramedullary interlocking nail and dynamic compression plating in fracture shaft of humerus and virtually no study in this part of world. Objective: The aim of the study was to assess the fixation of fracture shaft of humerus with interlocking nail and in terms of duration of operating time, amount of blood loss, rate of infection,pain at the fracture site,time to achieve union,functional outcome (DASH score), complications of surgery. Method: This was respective interventional study. All patients with fractures of shaft of humerus that met the criteria for operative interventions (intramedullary interlocking nail) presenting to the department of Orthopaedics BPKIHS over a period of 3 years from July 2006 to August 2009 and giving informed consent were included in the study. The study enrolled 30 patients. Result: Among 30 patients, $75 \%$ were male and $25 \%$ were female. The mean age of patients was 34.5 years. The usual mode of injury were road trafiic accident followed by fall from height, work place injury. Most of the patients were right handed. The operating time was 100 mins with standard deviation of 11.24. The mean blood loss was 148.75 with standard deviation of 36.70 . Post operative hospital stay was 4.5 days. The peroperative radial nerve palsy was $4 \%$. Radiologically, four cortices union was only $50 \%$ in 24 weeks post operative time. Dash score gradually improved in susequent followed up. Conclusion: It is concluded that dynamic compression plating is better in our study for fracture shaft of humerus. Plate osteosynthesis remains the gold standard of fixation for humeral shaft fractures.
\end{abstract}

Key words: Interlocking nail, plate fixation, shart of humerus

\footnotetext{
Address for correspondence

Dr. Pashupati Chaudhary

Additional Professor

Department of Orthopadics

B.P. Koirala Institute of Health Sciences, Dharan

Email: chaudharypashupati@yahoo.com
} 


\section{Introduction}

Fractures of the humeral diaphysis comprise approximately $3 \%$ of all fractures. ${ }^{1}$ The proportion of these fractures being treated conservatively reportedly varies from $33 \%{ }^{2}$ to $95 \% .^{3}$ Intramedullary fixation of humeral diaphyseal fractures ${ }^{4,5,6,7}$ as well as compression plating ${ }^{8,2,9}$ or external fixation in open fractures ${ }^{10}$ are described. Lin reported a near $100 \%$ union rate in 73 fractures treated with either locked intramedullary nails or compression plates and screws. ${ }^{11}$ He noted a significantly shorter operative time, less blood loss, and a lower complication rate with locked intramedullary nails. Chapman et al. found no difference in outcome or complication rate in an 84-patient, prospective, randomized study comparing Russell-Taylor locked intramedullary nails with $4.5-\mathrm{mm}$ compression plates and screws. ${ }^{11}$ Chapman et al. found no difference in outcome or complication rate in an 84patient, prospective, randomized study comparing Russell-Taylor locked intramedullary nails with 4.5-mm compression plates and screws. ${ }^{11}$ The optimal method of humeral shaft fracture fixation remains in debate. With the dramatic success of intramedullary fixation for fractures of the femur and tibia, there was speculation that IM-ILN might be more appropriate for humeral shaft fractures than DCP. In this study, it is believed that the theoretical advantages of IM-ILN (which include less invasive surgery, an undisturbed fracture hematoma, and use of a load-sharing device) support its use in the humerus ${ }^{12}$.

Humerus nailing has advantage in comminuted fracture and segmental fracture of shaft of humerus over humerus plating. Dynamic compression plating is gold standard for transverse stable fracture of shaft of humerus. Biomechanically intramedullary nailing can also be used in transeverse fracture of shaft of humerus ${ }^{1,2,3}$ There are very few studies comparing intramedullary interlocking nail and dynamic compression plating in fracture shaft of humerus and virtually no study in this part of world.

\section{Methods}

All patients with fractures of shaft of humerus that met the criteria for operative interventions intramedullary interlocking nailing presenting to the department of Orthopaedics BPKIHS in the study (Jun 2006 to August 2009) period and giving informed consent were included in the study. The Sample size were 30.The exclusion criteria were gustilo grade II and III open fractures shaft of humerus, periarticular fractures of humerus, fractures with associated neurovacular injury, bone and joint disease interfering with rehabilitation, primary nerve palsy, patients with active infection, 
candidates not giving informed consent, age less than with immature skeletal, pathological fractures.

The average follow-up was 6 months to 1 year. Patients were followed up on $2^{\text {nd }}$ week, $6^{\text {th }}$ week, $12^{\text {th }}$ week, and $24^{\text {th }}$ week and assessed for evidence, pain at the fracture site using visual analouge score (VAS score), evidence of union, functional outcome using DASH score.

\section{Statistical methods applied}

Variables like age, sex, involved limb, dominant limb, duration of injury, type of fracture, duration of operating time, amount of blood loss, rate of infection, pain at the fracture site, time to achieve union, functional oucome of shoulder and elbow, complications of surgery were tested by appropriate paremetric and non parametric statistical technique (e.g. T-test, Chisquare test) depending upon the natures of variables.

\section{Operative procedure}

\section{Intramedullary interlocking nail:}

Patients was placed in the beach chair, semisitting position, with affected arm draped free. The image intensifier is brought in directly laterally on the injured side and the patient is brought on the edge of the table [Fig 1].

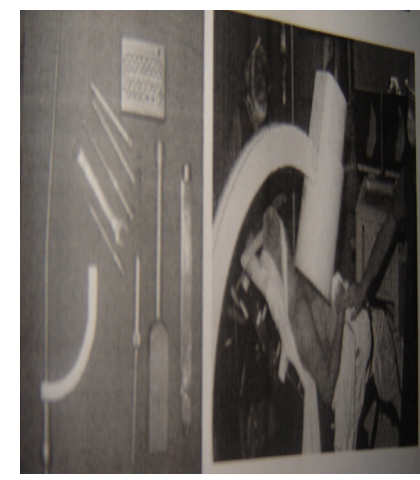

Fig.1: Image intensifier

It is important to check and ensure a good Xray of the entire humerus is possible. The surgeon stands at the top of the bed looking down on the shoulder and the assistant stands below on the other side of the image holding arm. A small incision was made at the anterolateral corner of the acromion, the deltoid was split and any visible subdeltoid bursa was excised [Fig 2].

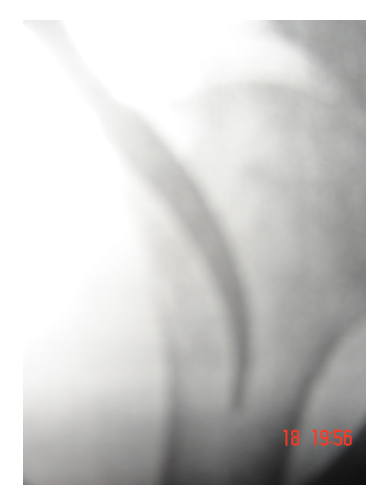

Fig. 2: Anterolateral approach

The supraspinatus tendon was identified, and split for 1-2 cm in line with its fibres. The entry point was in greater tuberosity, just lateral to the articular margin. The canal was broached 
with either an awl or a starter reamer placed over guide wire. A long guide wire was then passed to the fracture site, only nail greater than $6 \mathrm{~mm}$ in diametet was cannulated. Reamming was done till chattering sound of cortex was heard, and then insert a nail $1 \mathrm{~mm}$ smaller in diameter than last reamer used. The length of nail was carefully choosen and checked twice, put in the medullary cavity. The nail was then locked with screws using zig proximally and free hand technique distally [Fig: 3a,b,c,d].

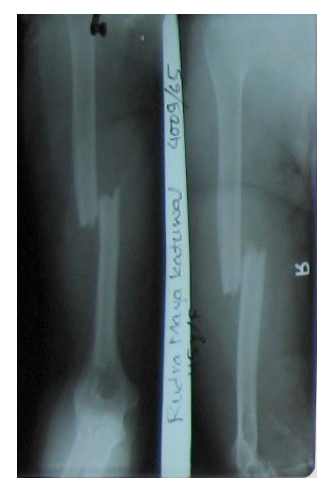

(a)

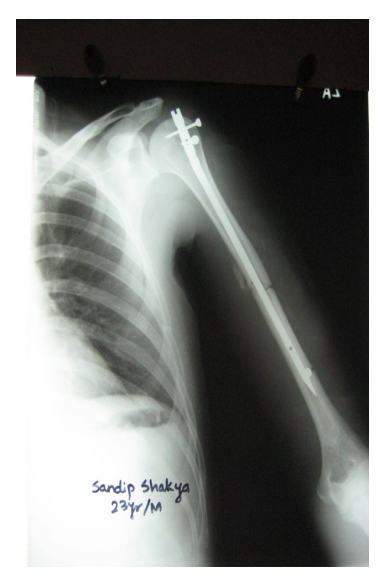

(c)

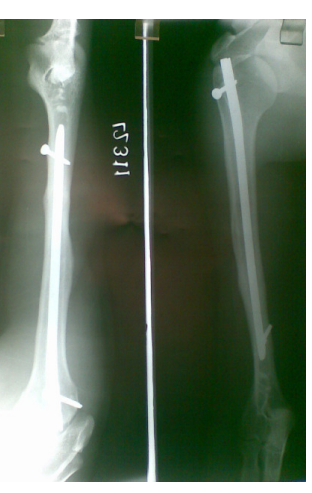

(b)

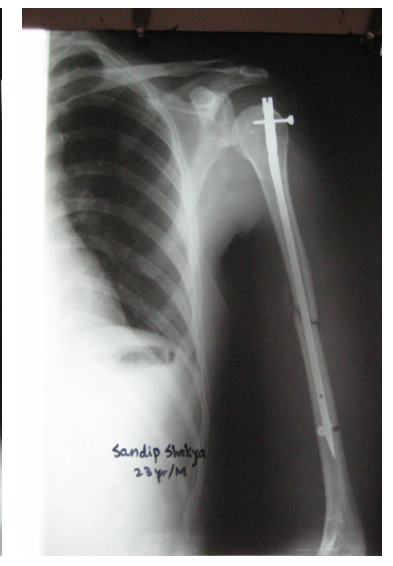

(d)
Fig 3: Pre operative and post operative $\mathrm{X}$ rays
Any split in rotator cuff was repaired, incision was closed in layers. Standard dressing was applied, no external splint was applied.

\section{Results}

Out of 30 patients participated in the study, $75 \%$ were male and $25 \%$ were female. The mean age of patients was 34.5 years.

The usual mode of injury were road trafiic accident followed by fall from height, work place injury. Most of the patients were right handed. Mean surgery interval was 23.1 days. The operating time for nailing was 100 mins with standard deviation of 11.24 . The mean blood loss in nail group was 148.75 with standard deviation of 36.70. Post operative hospital stay was mean stay of 4.5 days. The peroperative radial nerve palsy was $4 \%$. Out of 30 patients 3 patients got superficial infection which was subsided with intravenous antibiotics. In 2 patients, there were iatrogenic fracture communication. There was no tenderness at fracture site on attempted angulation till 12 weeks follow up. Dash score gradually improved in 24 weeks follow up but 5 patients had stiffness of shoulder joint, most probably due to injury to rotator cuff [Fig:5a,b]. 


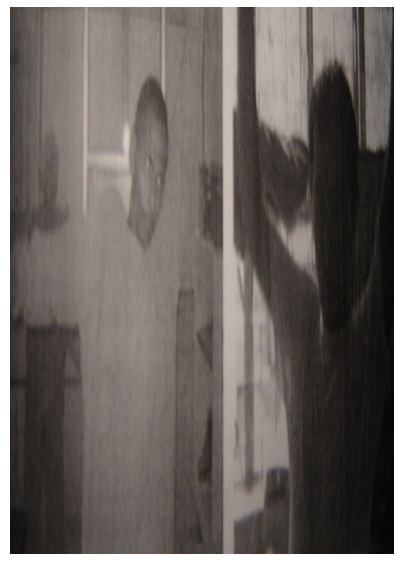

(a)

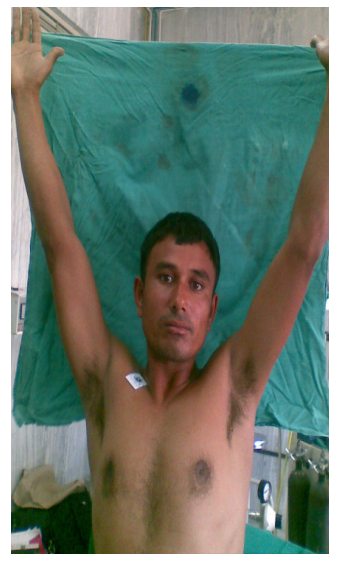

(b)
Fig. 5: Functional outcome

Radiologically, four cortices union was only $50 \%$ in 24 weeks post operative time. Union was delayed due to distraction at the fracture site during nail insertion. There was implant failure in 1 patient [Fig: 4].
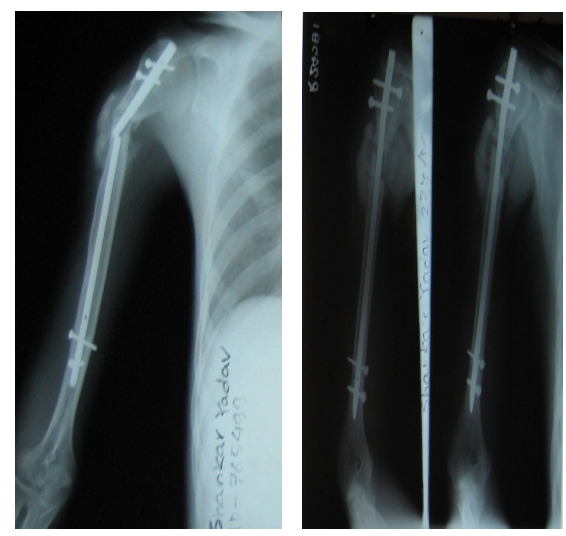

Fig 4: Post operative X-rays with inplant failure

\section{Discussion}

In the study by changulani $\mathrm{M}$ et al. $^{13} 86.9 \%$ were males and $13 \%$ females. The mean age of the patients was 39 years. The mean age of patients was 45.3 years in the study conducted by $S$ Raghavendra et al. The operating time is more in our study which in in contrary to the study done by Lin who had found shorter operating time. This may be due to poor expertise of surgeon, unavailability of trained person to operate image intensifier. The introperative blood loss is less most probably due to less invasive technique used which is comparable with study done by $\operatorname{Lin}^{15}$.

Post operative hospital stay and post operative infection are comparable with done by S Raghvendra, Haresh Bhalodiya. Raghvendra $\mathrm{S}$ et $\mathrm{al}^{14}$. had found better outcome.Usually distraction at the fracture during insertion lead to delayed union of fracture in Intramedullary interlocking nail. Raghvendra S et al study also had concluded delayed union

Brumback RJ et al.(1986) reported a 94\% union rate with rush pins and Enders although there was a significant rate of insertion site morbidity and backing out of the nails such that the excellent clinical success rate was much lower (62\%).

Henley (1992) reported a series of 49 patients with humeral shaft fractures treated with Ender nailing and had only one nonunion which is similar to our present study as there is also only one case of nonunion.

Imgman AM et al (1994) showed that closed locked intramedullary nailing for humeral shaft fractures can realibly provide secure 
fixation with acceptable risks which seems to be same as our study which also shows same results.

\section{Conclusion}

Intramedullary interlocking nailing is less invasive procedure with advantages of less blood loss for fracture shaft of humerus. There may be delay in union in nailing due to distraction at the fracture site which usually occurs during nail insertion. Poor outcome in intramedullary interlocking nailing is attributable to rotator cuff tear and shoulder impingement and lack of expertise of surgeon.

Locking humeral nails were introduced with hope that results from their use would parallel the clinical success seen with similar devices used for femoral and tibial fractures. Unfortunately, despite favourable initial reports, these devices have not enjoyed the unparalled success of lower extremity locking nails.

The limitation of this study is that it is done in single centre and had less number of patients so further randomized control trial needed.

\section{References}

1. Canale ST. Campbell's Operative Orthopaedics, 1oth ed, 2003; 3(54); 30023016. Philadelphia: MOSBY.

2. Canale ST, Beaty Jh. Campbelll's Operative Orthopaedics,11th ed,volume
II954); 3389-3398. Philadelphia: Mosby Elsevier; 2008

3. Bucholz Rw, Heckman JD, Court- Brown CM. Rockwood \& Green's fractures in adults,6th ed,volume I(30); 117-1159. Lippincott Williams \& Wilkins: 2006

4. Schemitsch EH, Bhandari M. Fractures of the diaphyseal humerus. In: Browner BD, Jupiter JB,Levine AM, Trafton PG,eds. Skeletal trauma, 3rd ed. Toronto: WB Saunders; 2001:1481-1511

5. Praemer A, Furner S, Rice DP. Musculoskeletal conditions in the United states. rosement,IL: americal Academy of Orthopaedic Surgeons; 1999

6. Brinker MR, OÇonnor DP. The incidence of fractures and dislocations referred for Orthoapedic services in a capitated population. J Bone Joint Surg Am 2004; 86:290-297

7. Gregory PR. Fractures of the humeral shaft. In : Bucholz RW, Heckman JD, eds. Rockwood and green's fractures in adults, 5th ed. Philadelphia: Lippincoat Williams \& Wilkins; 2001: 973-996

8. Fears RL, Gleis GE, Selingson D. Diagnosis and tratment of complications: Fractures of the diaphyseal humerus. In: Browner BD,Jupiter JB,Levine AM,Trafton $P G$, eds. Skeletal trauma, 2nd ed. Toronto: WB Saunders. 1998; 567-578

9. Samiento A, Zagorski JB,Zych $G$ et al. Functional bracing for the treatment of 
fractures of the humeral diaphysis. $J$ Bone Joint Surg Am 2008; 82: 478-486

10. Standard JP, Harris Hw, Mcgwin G Jr, et al. Intramedullary nailing of humeral shaft fractures with a locking, flexible. J Bone Joint Surg Am 2003; 85: 2103-2110

11. Tytherleigh- Strong G, walls N, Mcqueen NM. The epidemiology of humeral shaft fractures. J Bone Joint Surg Am 1998; 80: 249-253

12. Sommer C, Gautier E, Muller M, et al. First clinical results of the locking compression Plate(LCP). Injury 2003; 34 ( suppl 2): B43-54

13. Changulani M, Jain UK and Keswani T. Comparation of use of the humerus intramedullary nail and dynamic compression plate for the management of diaphyseal fractures of humerus, A randomised controlled study, International Orthopaedics, Springer- Verlag 2006; 10.1007/s00264-006-0200-1

14. Radhavendra S, Bhalodiya HP. Internal fixation of fractures of the shaft of the humerus by dynamic compression plate or intramedullary nail: A prospective study. Indian J Orthop ( serial online) 2007( cited 2009 Jul 1)41:214-8

15. Lin J Treatment of humeral shaft fractures with humeral locked nail and comparasion with plate fixation J Trauma 1998; 44: 859

16. Vander Griend RA, Tomasin J, et al. Open reduction and internal fixation of humeral shaft fractures. J Bone Joint Surg Am 1986; 68: 430-433.

17. Brumback RJ, Bosse MJ, Poka A, et al. Intramedullary stabilization of humeral shaft fractures in patients with multiple trauma. J Bone Joint Surg Am 1986; 68: 960-969.

18. Henley MB, Champmn JR,Claudi BF. Closed retrograde Hackethal nail stabilization of humeral shaft fractures. $J$ Orthop Trauma 1992; 6:18-24

19. Imgman AM, Waters DA. Locked intramedullary nailing of humeral shaft fractures implant design, surgical technique and clinical results, $J$ Bone Joint Surg (Br) 1995;77-B:84-89 